\title{
Erratum
}

\section{Minimally invasive removal of thoracic and lumbar spinal tumors using a nonexpandable tubular retractor}

\section{Clinical article}

To THE EDITOR: We appreciate publication of our paper entitled "Minimally invasive removal of thoracic and lumbar spinal tumors using a nonexpandable tubular retractor. Clinical article" (J Neurosurg Spine 19:708-715, 2013).

After publication of this article, Drs. Tan and O'Toole ${ }^{1}$ drew our attention to an error that appeared in the paper's introduction. Originally, the second-to-last sentence of the Introduction read,

We report our experience with the minimally invasive removal of extradural foraminal and intradural-extramedullary tumors using the 18-mm nonexpandable Spotlight Access System (DePuy Spine).

This statement was incorrect; in fact, 18 - to 24-mm tubes were used in this case series. This sentence has been changed to the following:

We report our experience with minimally invasive removal of extradural foraminal and intradural-extramedullary tumors using the SPOTLIGHT Access System with nonexpandable tube retractors ranging from 18 to $24 \mathrm{~mm}$ (DePuy Spine).

We thank Drs. Tan and O'Toole and apologize to the editor and readers. We are pleased to have the opportunity to make this correction, which has been posted online as of March 7, 2014.

Andre NzoKou, M.D.

Alexander G. Weil, M.D., F.R.C.S.C. DANIEl SHedid, M.D., M.Sc., F.R.C.S.C.

Notre Dame Hospital

University of Montreal

Montreal, QC, Canada

\section{Reference}

1. Tan LA, O’Toole JE: Tubular retractor selection in minimally invasive spinal tumor resection. J Neurosurg Spine [epub ahead of print March 7, 2014. DOI: 10.3171/2013.10.SPINE 13944] (Letter)
Please include this information when citing this paper: published online March 7, 2014; DOI: 10.3171/2014.1.SPINE121061a. 